\title{
Assessing severity of cardiac sarcoid: Is SUV the answer?
}

\author{
Stephanie Montalto, MBBS, ${ }^{\mathrm{a}}$ and Nathan Better, MBBS, FRACP, ${ }^{\mathrm{a}, \mathrm{b}, \mathrm{c}}$ \\ a Department of Cardiology, Royal Melbourne Hospital, Parkville, VIC, Australia \\ b Department of Nuclear Medicine, Royal Melbourne Hospital, Parkville, VIC, Australia \\ c Department of Medicine, University of Melbourne, Parkville, VIC, Australia
}

Received Nov 11, 2018; accepted Nov 12, 2018

doi: $10.1007 / \mathrm{s} 12350-018-01534-6$

\section{See related article, pp. 2003-2010}

The challenges involved in the diagnosis of cardiac sarcoidosis are significant; however once the diagnosis has been successfully made, the journey has only just begun. Assessing severity of cardiac sarcoidosis (CS) may be crucial in predicting the clinical course, thereby guiding initial therapy-both medical and device therapy-and is often subsequently helpful in evaluating response to such therapies.

If we could establish reliable and reproducible markers of disease severity which correlate with adverse outcomes, a validated severity index could be utilized at the time of diagnosis to help risk stratify patients, and guide therapy; either towards more aggressive immunosuppression or away from unnecessary intervention in low risk disease.

The current method of assessing severity is based mostly on expert opinion. ${ }^{1}$ There are no practice guidelines to assist in risk stratification, and there are a number of mostly clinical parameters that are utilized.

\section{WHAT DOESN'T WORK IN RISK STRATIFICATION?}

\section{Traditional Risk Factors}

Usual cardiovascular risk calculators, such as the Framingham Risk Score and the ACC/AHA risk score,

\footnotetext{
Reprint requests: Nathan Better, MBBS, FRACP, Department of Nuclear Medicine, Royal Melbourne Hospital, Parkville, VIC, Australia; nathan.better@mh.org.au

J Nucl Cardiol 2020;27:2011-6.

$1071-3581 / \$ 34.00$

Copyright (C) 2018 American Society of Nuclear Cardiology.
}

have been found to be ineffective in predicting risk of cardiovascular events in the sarcoidosis population. In fact, both scores significantly underestimate the risk of major adverse cardiac events (MACE) by 2-5 fold, likely reflecting the additional risk conveyed by the acute or chronic inflammatory state (like that seen in rheumatoid arthritis). ${ }^{2}$ Furthermore, neither age, the Japanese Ministry for Health \& Welfare criteria nor the presence of extra-cardiac sarcoidosis were associated with increased adverse events in a CS cohort. ${ }^{3}$ Similarly, baseline ECG abnormalities are of limited benefit in either diagnosis or risk stratification. ${ }^{4}$ Traditional prognostic markers such as New York Heart Association (NYHA) functional class, left ventricular end-diastolic diameter (LVEDD), and the presence of sustained ventricular tachycardia were shown to be independent predictors of mortality in $\mathrm{CS}^{5}$; however, ideally the clinician would like to intervene prior to the development of heart failure, cardiomyopathy or the first instance of a potentially lethal arrhythmia.

\section{Presence/Absence of Extra-Cardiac Sarcoidosis}

It remains unclear whether a concurrent diagnosis of extra-cardiac sarcoidosis conveys mortality benefit, or is a poor prognostic sign. There have been a number of recent studies examining the increased morbidity and mortality reported in the group of CS patients found to have isolated cardiac sarcoidosis. However, there are multiple biases inherent in the analysis of this group. CS in the presence of extra-cardiac sarcoidosis is frequently diagnosed after asymptomatic screening, while those with isolated cardiac sarcoidosis have more often presented with a primary cardiac complaint. ${ }^{6}$ 


\section{Biomarkers}

Serum ACE levels have been historically used; however, the poor sensitivity in the CS population (elevated in only $60 \%$ of patients) renders it a test of very limited utility. Furthermore, the degree of elevation has not been found to correlate with disease severity in any sarcoidosis population. ${ }^{7}$

Elevated serum soluble IL-2 receptor and serum lysozyme have also been identified as being of use in the diagnosis of sarcoidosis; however, there is no correlation between serum levels and disease severity.

Significant lymphopenia involving CD4-, CD8-, and CD19-positive cells is common in sarcoidosis patients and has been shown to correlate with disease severity. However, this has not been studied in the CS population. ${ }^{8}$

Micro-RNA, in particular miR-126 and miR-223 may have potential use in the future for diagnosis and prognostication in sarcoidosis. A correlation between the degree of abnormality in a 17-gene signature in the JakSTAT signaling pathway and the severity of sarcoidosis has been recently reported. ${ }^{9}$ The gene was also found to differentiate between sarcoidosis patients and healthy controls. Another genetic polymorphism, FCGR2A and FCGR2C, has been identified as a potential tool in predicting clinical course of sarcoidosis. ${ }^{10}$

\section{Histopathology}

Endomyocardial biopsy showing non-necrotising granulomas is the gold standard of diagnosis of CS. However, due to the focal myocardial involvement, sensitivity is relatively low. Histological markers do not currently convey prognostic information beyond diagnosis in cardiac sarcoidosis. ${ }^{1}$

\section{Electrophysiology studies}

Electrophysiology studies identifying inducible arrhythmias and 'at-risk' substrates are sometimes used to risk stratify patients with CS; however, their use has not been validated and routine use is not currently recommended. ${ }^{11,12}$

\section{CURRENT APPLICATION OF IMAGING TECHNIQUES IN ASSESSMENT OF SEVERITY}

\section{Echocardiography}

Typical abnormalities found on transthoracic echocardiography include regional wall motion abnormalities not consistent with a vascular territory, particularly the basal septum. LV dilatation and systolic or diastolic dysfunction may be present, as can right ventricular dysfunction. However, none of these parameters have been proven to correlate well with risk of future adverse events.

Echocardiography is insensitive in the detection of early stages of disease and a normal echocardiogram does not exclude the presence of significant cardiac involvement in a patient with systemic sarcoidosis.

There have been recent studies examining the application of strain imaging in early detection of regional wall motion abnormalities. A recent study in CS patients found an inverse relationship between global longitudinal strain (GLS) magnitude and the more sensitive measure of late gadolinium enhancement (LGE) burden on cardiac MRI (CMR), raising GLS as a possibly useful measure of disease severity. ${ }^{13}$

\section{Cardiac Magnetic Resonance Imaging (CMR)}

Typical findings are of sub-epicardial and mid-wall myocardial enhancement, particularly in the basal and lateral segments. There can also be subendocardial or transmural changes, and this may also be present in the right ventricular free wall. CMR can also aid in detection of regional wall motion abnormalities and areas of thinned myocardium. RV LGE (in addition to LV disease) has been found to carry higher risk, possibly due to involvement of a larger overall amount of myocardium or a more arrhythmogenic substrate ${ }^{14}$ LGE in a non-ischaemic distribution has been shown to be a better predictor of adverse outcomes than ejection fraction.

LGE has been found to correlate with significantly more ventricular arrhythmias in the CS population, ${ }^{15}$ as well as all adverse events. ${ }^{16}$ When added to positive cardiac fluorodeoxyglucose positron emission tomography (FDG-PET), the presence of LGE identifies the group at highest risk of MACE among the CS population. ${ }^{17}$

In current literature, LGE is largely used as a binary measure. Therefore, the utility of CMR as a quantitative measure of disease severity is limited.

Future studies examining the use of $\mathrm{T} 1$ and $\mathrm{T} 2$ mapping suggest a possible benefit in the identification of oedema or inflammation, compared with the fibrosis detected by LGE. The role of such mapping in assessing severity is still unknown.

\section{SPECT Imaging}

Gallium-67 scintigraphy, while still included in the HRS Consensus Statement for diagnosis of cardiac sarcoidosis, has been almost entirely replaced by PET scan in the modern era. ${ }^{18}{ }^{201} \mathrm{Tl}-\mathrm{SPECT},{ }^{99 \mathrm{~m}} \mathrm{Tc}$ MIBI 
SPECT, and ${ }^{82} \mathrm{Rb}$ PET, showing perfusion defects have also fallen in usage in favor of the improved sensitivity and better image quality of PET and CMR. The perfusion tracers are still often used together with FDG-PET to evaluate metabolism-perfusion mismatch.

\section{FDG PET}

PET has multiple advantages over other imaging modalities in the investigation of CS. PET is more sensitive in identifying areas of active inflammation and can therefore be used to monitor response to therapy. Many patients in the CS cohort have cardiac devices in situ, and therefore MRI can be contra-indicated. There is also no requirement for potentially nephrotoxic contrast. ${ }^{18}$ PET and MRI often provide complementary information, and when combined currently provide the most accurate risk stratification available. ${ }^{14}$

\section{CURRENT EVIDENCE IN FDG PET}

The article by Flores et al, ${ }^{19}$ published in today's issue, aims to add to the current body of evidence suggesting benefit in the use of FDG PET in risk stratification of patients with CS. Their study used a number of different quantitative and semi-quantitative measures of FDG uptake in the PET scans of $67 \mathrm{CS}$ patients, and aims to relate the severity of FDG uptake with clinical outcomes. While a number of studies have examined the prognostic role of PET in CS, this trial is one of the first to firmly assess quantitative standardized uptake values (SUV) measures for both global and segmental location, in an effort to begin the journey towards formalized reference ranges for severity that could reliably risk stratify and therefore help guide therapy.

67 PET scans were analyzed and max SUV, mean SUV, localisation of FDG uptake by segment and LV ejection fraction (LVEF) were all recorded. There are yet no concrete subdivisions of severity by FDG in CS; therefore, each odds ratio was calculated per 1 point increment in mean and max SUV, with average max SUV in diseased segments being 5.4. Both SUV max and mean were shown to have a statistically significant correlation with total cardiac events. Additionally, location of FDG uptake was analyzed. $91 \%$ of scans were found to have evidence of disease in basal segments, with an elevated mean SUV in the basal segments found to be independently significant in correlating with cardiac events.

An obvious criticism of Flores' study is the retrospective nature of the trial. Looking forward, further trials should aim to first validate and ultimately utilize PET severity criteria to help guide prospective therapy and assess outcomes. Additionally, clinicians were not blinded to PET result and therefore severity of inflammation on PET was likely considered when determining course of therapy, with possibly more intensive immunosuppression or prophylactic device insertion performed in those patients with a higher degree of inflammation.

While efforts were made to record evidence of arrhythmias such as ventricular tachycardia, complete heart block or atrial fibrillation, as well as new device placement, a thorough cataloguing of all device checks (either new or old) was not able to be performed, leaving any subclinical arrhythmia unrecorded. Considering the large proportion of patients with either implanted defibrillator or pacemaker devices in situ at the commencement of the trial (55\% and 59\% respectively) this is a significant omission. In addition, any events resulting in presentation to alternative centers were not recorded. These missing data culminated in an overall lower average event rate than other trials in comparable CS cohorts.

Despite the above criticisms, the authors should be praised for maintaining a cohort of 67 patients over a 3year follow-up period in such a rare condition. This study was able to forge a path towards several statistically significant conclusions of great potential clinical relevance. 
Other Papers Using FDG Quantification

\begin{tabular}{|c|c|c|c|c|}
\hline Article & Patient group & $\begin{array}{c}\text { PET parameter } \\
\text { used }\end{array}$ & Median follow-up & Results \\
\hline Blankstein et al $^{14}$ & $\begin{array}{l}125 \text { pts with } \\
\text { suspected CS }\end{array}$ & $\begin{array}{l}\text { - Binary FDG uptake } \\
\text { - Binary focal } \\
\text { perfusion defects }\end{array}$ & 17 months & $\begin{array}{c}\text { HR } 2.7 \text { ( } p<0.01 \text { ) of } \\
\text { death or sustained } \\
\text { VT in PET positive }\end{array}$ \\
\hline McArdle et $\mathrm{al}^{20}$ & $\begin{array}{l}20 \text { pts with CS + AV } \\
\text { block or CS + VT vs } \\
\text { clinically silent CS } \\
\text { controls }\end{array}$ & $\begin{array}{l}\text { - Mean SUV } \\
\text { - Max SUV }\end{array}$ & $\mathrm{N} / \mathrm{A}$ & $\begin{array}{l}\text { Mean and max SUV } \\
\text { higher in VT group } \\
\text { vs AV block } \\
(P=.016 \text { and } \\
P=.005) \text { and vs } \\
\text { controls }\end{array}$ \\
\hline Muser et $\mathrm{al}^{21}$ & $\begin{array}{l}20 \text { pts with } \mathrm{CS}+\mathrm{VT} \\
\text { over } 92 \text { serial scans }\end{array}$ & $\begin{array}{l}\text { - Max SUV } \\
\text { - Mean SUV } \\
\text { - Lesion metabolic } \\
\text { activity (LMA) }\end{array}$ & 35 months & $\begin{array}{l}\text {-Poor response }(\mathrm{LMA} \\
\text { decrease by }<25 \%) \\
\text { asspciated with } 20 \text { - } \\
\text { fold increase in } \\
\text { MACE }(P=0.007) \\
\text {-Inverse linear } \\
\text { relationship } \\
\text { between change in } \\
\text { LMA and change in } \\
\text { LVEF }(P=.003)\end{array}$ \\
\hline Ahmadian et $\mathrm{al}^{22}$ & $\begin{array}{l}17 \text { pts with CS over } 43 \\
\text { serial scans pre- and } \\
\text { post-treatment }\end{array}$ & $\begin{array}{l}\text { - Number of FDG- } \\
\text { positive } \\
\text { segments } \\
\text { - Max SUV } \\
\text { - Cardiac metabolic } \\
\text { volume } \\
\text { - Cardiac metabolic } \\
\text { activity } \\
\text { - Volume above } \\
\text { SUV thresholds of } \\
2.7 \text { and } 4.1 \mathrm{~g} / \mathrm{mL}\end{array}$ & 9.6 months & $\begin{array}{l}\text { - Reduction in CMA } \\
\text { and CMV more } \\
\text { frequently identified } \\
\text { full response to } \\
\text { treatment } \\
\text {-Partial responders } \\
\text { had higher max SUV } \\
\text { post-treatment } \\
\text { (p }<0.001 \text { ) and } \\
\text { higher volume } \\
\text { above } 2.7 \mathrm{~g} / \mathrm{mL} \\
\text { threshold } \\
(p<0.001)\end{array}$ \\
\hline Ahmadian et al $^{23}$ & $\begin{array}{l}38 \text { pts with CS vs. } \\
\text { negative controls }\end{array}$ & $\begin{array}{l}\text { - Cardiac metabolic } \\
\text { activity (CMA) }\end{array}$ & $\mathrm{N} / \mathrm{A}$ & $\begin{array}{l}\text {-CMA greater in } \\
\text { visually positive } \\
\text { studies vs visually } \\
\text { negative and } \\
\text { Controls }(P=.02) \\
\text {-CMA greater in } \\
\text { LVEF }<50 \% \\
(P=.03) \text { and } \\
\text { preceding a MACE } \\
(P=.006) \\
\text {-CMA reduced with } \\
\text { steroids in } 5 \text { of } 6 \text { pts }\end{array}$ \\
\hline
\end{tabular}




\begin{tabular}{|c|c|c|c|c|}
\hline Article & Patient group & $\begin{array}{c}\text { PET parameter } \\
\text { used }\end{array}$ & Median follow-up & Results \\
\hline Lee et $\mathrm{al}^{24}$ & $\begin{array}{c}16 \text { pts with CS over } 54 \\
\text { serial scans pre and } \\
\text { post-treatment }\end{array}$ & $\begin{array}{l}\text { - Max SUV } \\
\text { - Mean SUV } \\
\text { - Cardiac metabolic } \\
\text { volume (CMV) } \\
\text { - Global metabolic } \\
\text { volume }\end{array}$ & 8.7 months & $\begin{array}{l}\text {-All } 4 \text { parameters } \\
\text { significantly } \\
\text { decreased in pts } \\
\text { classified as stable/ } \\
\text { improved. } \\
\text { Significant only for } \\
\text { max SUV ( } P=.03) \\
\text { and mean SUV } \\
(P=.04) \\
\text {-All pts who } \\
\text { deteriorated had no } \\
\text { change to PET scan }\end{array}$ \\
\hline Osborne et $\mathrm{al}^{25}$ & $\begin{array}{l}23 \text { pts with CS over } 92 \\
\text { serial scans }\end{array}$ & $\begin{array}{l}\text { - Max SUV } \\
\text { - Volume above } \\
\text { SUV } 2.7 \mathrm{~g} / \mathrm{mL} \\
\text { and } 4.1 \mathrm{~g} / \mathrm{mL}\end{array}$ & 2 years & $\begin{array}{l}\text {-Inverse linear } \\
\text { relationship } \\
\text { between max SUV } \\
\text { vs LVEF }(P=.008), \\
\text { also between } \\
\text { volume above } \\
2.7 \mathrm{~g} / \mathrm{mL} \text { and } 4.1 \mathrm{~g} / \\
\mathrm{mL} \text { vs LVEF } \\
(P=.028,=.022)\end{array}$ \\
\hline Sperry et $\mathrm{al}^{26}$ & $\begin{array}{l}203 \text { pts with } \\
\text { suspected CS }\end{array}$ & $\begin{array}{l}\text { - Binary perfusion/ } \\
\text { metabolism } \\
\text { - Summed score of } \\
\text { resting perfusion } \\
\text { defects in } \\
\text { segments with } \\
\text { FDG + ve }\end{array}$ & 1.8 years & $\begin{array}{l}\text {-Higher summed } \\
\text { score associated } \\
\text { with increased } \\
\text { MACE }(P=.029)\end{array}$ \\
\hline 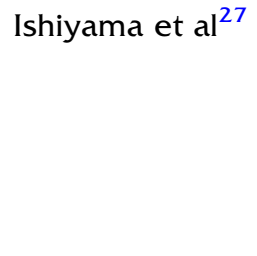 & $\begin{array}{l}16 \text { pts with suspected } \\
\text { CS pre and post- } \\
\text { treatment }\end{array}$ & $\begin{array}{l}\text { - Max SUV across } \\
\text { all organs } \\
\text { - Max SUV (cardiac) }\end{array}$ & 6 months & $\begin{array}{l}\text {-Only lower max SUV } \\
\text { in all organs } \\
\text { associated with } \\
\text { lower steroid dose } \\
\text { at } 6 \text { months } \\
(P=.04)\end{array}$ \\
\hline
\end{tabular}

\section{WHERE TO FROM HERE?}

More streamlined diagnostic pathways and severity scoring, both at time of diagnosis and for assessing response to therapy in cardiac sarcoidosis are needed. Multiple new technologies across the spectrum of imaging modalities are currently being trialed, as are multi-modal imaging platforms. The use of $\mathrm{T} 1$ and $\mathrm{T} 2$ mapping for early detection of inflammation on MRI, late enhancement on cardiac $\mathrm{CT}^{28}$ and integrated PET/ MRI scanners are techniques that have shown promise and are now being investigated in larger trials. A recent pilot study utilizing a sarcoid-specific radiotracer (68-
Ga-DOTA-NaI-octreotide) found it to be superior to standard FDG-PET in diagnosing $\mathrm{CS}^{29}$

As seen in the above literature review, different groups are utilizing various measures of FDG uptake, often with successful prediction of future clinical events, or response to therapy. Larger trials are needed, recording a number of different quantitative measures, to accurately establish which measures are of greatest utility in the staging of CS. Ideally, a combination of multi-modality imaging factors could be used to generate a severity score, which potentially will accurately predict MACE in CS, and hence offer the clinician a 
valuable tool to guide therapy; SUV may prove to be this tool.

\section{Disclosure}

None of the authors have any disclosures.

\section{References}

1. Ho JSY, Chilvers ER, Thillai M. Cardiac sarcoidosis: An expert review for the chest physician. Expert Rev Respir Med 2018;3:114.

2. Ungprasert P, Matteson EL, Crowson CS. Reliability of cardiovascular risk calculators to estimate accurately the risk of cardiovascular disease in patients with sarcoidosis. AM K Cardiol 2017;120:868-73.

3. Blankstein R, Waller A. Evaluation of known or suspected cardiac sarcoidosis. Circ Cardiovasc Imaging 2016;9:e000867.

4. Nagao S, Watanabe H, Sobue Y, et al. Electrocardiographic abnormalities and risk of developing cardiac events in extracardiac sarcoidosis. Int J Cardiol 2015;189:1-5.

5. Yazaki Y, Isobe M, Hiroe M, et al. Prognostic determinants of long-term survival in Japanese patients with cardiac sarcoidosis treated with prednisone. Am J Cardiol 2001;88:1006-10.

6. Okada DR, Bravo PE, Vita T, et al. Isolated cardiac sarcoidosis: A focused review of an under-recognized entity J Nucl Cardiol. 2018;25:1136

7. Iannuzzi MC, Rybicki BA, Teirstein AS. Sarcoidosis. N Engl J Med 2007;357:2153-65.

8. Sweiss NJ, Salloum R, Gandhi S, et al. Significant CD4, CD8, and CD19 lymphopenia in peripheral blood of sarcoidosis patients correlates with severe disease manifestations. PLoS ONE 2010;5:e9088

9. Zhao T, Casanova N, Pouladi N, et al. Identification of Jak-STAT signaling involvement in sarcoidosis severity via a novel microRNA-regulated peripheral blood mononuclear cell gene signature. Sci Rep 2017;7:4237.

10. Typiak M, Rebala K, Dudziak M, et al. Polymorphism of FCGR2A, FCGR2C, and FCGR3B genes in the pathogenesis of sarcoidosis. Adv Exp Med Biol 2016;905:57-68.

11. Mehta D, Mori N, Goldbarg SH, et al. Primary prevention of sudden cardiac death in silent cardiac sarcoidosis: Role of programmed ventricular stimulation. Circ Arrhythm Electrophysiol 2011;4:43-8.

12. Aizer A, Stern EH, Gomes JA, et al. Usefulness of programmed ventricular stimulation in predicting future arrhythmic events in patients with cardiac sarcoidosis. Am J Cardiol 2005;96:276-82.

13. Murtagh G, Laffin LJ, Patel KV, et al. Improved detection of myocardial damage in sarcoidosis using longitudinal strain in patients with preserved left ventricular ejection fraction. Echocardiography 2016;33:1344-52.

14. Blankstein R, Osborne M, Naya M, et al. Cardiac positron emission tomography enhances prognostic assessments of patients with suspected cardiac sarcoidosis. J Am Coll Cardiol 2014;63:329-36.

15. Crawford T, Mueller G, Sarsam S, et al. Magnetic resonance imaging for identifying patients with cardiac sarcoidosis and preserved or mildly reduced left ventricular function at risk of ventricular arrhythmias. Circ Arrhythm Electrophysiol 2014;7:1109-15.

16. Kouranos V, Tzelepis GE, Rapti A, et al. Complementary role of CMR to conventional screening in the diagnosis and prognosis of cardiac sarcoidosis. JACC Cardiovasc Imaging 2017;10:1437-47.

17. Wicks EC, Menezes LJ, Barnes A, et al. Diagnostic accuracy and prognostic value of simultaneous hybrid ${ }^{18} \mathrm{~F}$-fluorodeoxyglucose positron emission tomography/magnetic resonance imaging in cardiac sarcoidosis. Eur Heart J Cardiovasc Imaging 2018;19:75767.

18. Chareonthaitawee P, Beanlands RS, Chen W, et al. Joint SNMMIASNC expert consensus document on the role of 18F-FDG PET/ $\mathrm{CT}$ in cardiac sarcoid detection and therapy monitoring. J Nucl Cardiol 2017;24:1741.

19. Flores R, Flaherty $\mathrm{K}$, Jin $\mathrm{Z}$ et al. The prognostic value of quantifying and localizing F-18 FDG uptake in cardiac sarcoidosis. $\mathrm{J}$ Nucl Cardiol.

20. McArdle BA, Birnie DH, Klein R, et al. Is there an association between clinical presentation and the location and extent of myocardial involvement of cardiac sarcoidosis as assessed by ${ }^{18} \mathrm{~F}$ fluorodoexyglucose positron emission tomography? Circ Cardiovasc Imaging 2013;6:617-26.

21. Muser D, Santangeli P, Castro SA, et al. Prognostic role of serial quantitative evaluation of ${ }^{18} \mathrm{~F}$-fluorodeoxyglucose uptake by PET/ $\mathrm{CT}$ in patients with cardiac sarcoidosis presenting with ventricular tachycardia. Eur J Nucl Med Mol Imaging 2018;45:1394-404.

22. Ahmadian A, Pawar S, Govender P, et al. The response of FDG uptake to immunosuppressive treatment on FDG PET/CT imaging for cardiac sarcoidosis. J Nucl Cardiol 2017;24:413-24.

23. Ahmadian A, Brogan A, Berman J, et al. Quantitative interpretation of FDG PET/CT with myocardial perfusion imaging increases diagnostic information in the evaluation of cardiac sarcoidosis. $\mathbf{J}$ Nucl Cardiol 2014;21:925-39.

24. Lee PI, Cheng G, Alavi A. The role of serial FDG PET for assessing therapeutic response in patients with cardiac sarcoidosis. J Nucl Cardiol 2017;24:19-28.

25. Osborne MT, Hulten EA, Singh A, et al. Reduction in ${ }^{18} \mathrm{~F}$-fluorodeoxyglucose uptake on serial cardiac positron emission tomography is associated with improved left ventricular ejection fraction in patients with cardiac sarcoidosis. J Nucl Cardiol 2014;21:166-74.

26. Sperry BW, Tamarappoo BK, Oldan JD, et al. Prognostic impact of extent, severity, and heterogeneity of abnormalities on ${ }^{18} \mathrm{~F}-\mathrm{FDG}$ PET scans for suspected cardiac sarcoidosis. JACC Cardiovasc Imaging 2018;11:336-45.

27. Ishiyama M, Soine LA, Vesselle HJ. Semi-quantitative metabolic values on FDG PET/CT as predictor of treatment course. EJNMMI Res 2017;7:67.

28. Aikawa T, Oyama-Manabe N, Naya M, et al. Delayed contrastenhanced computed tomography in patients with known or suspected cardiac sarcoidosis: A feasibility study. Eur Radiol 2017:27:4054-63.

29. Gormsen LC, Haraldsen A, Kramer S, et al. A dual tracer (68)GaDOTANOC PET/CT and (18)F-FDG PET/CT pilot study for detection of cardiac sarcoidosis. EJNMMI Res. 2016;6:52. 